\title{
Entre o violoncelo e o cavaquinho: música e sujeito popular em Machado de Assis
}

Idelber Avelar

Representados numa tensão entre criadores e executores, a ópera, o sonatismo, a valsa, a polca e o nunca nomeado maxixe assumem, em Machado de Assis, o caráter de cifra simbólica de algumas tensões na cultura brasileira. A obra machadiana registra um leque de figuras envolvidas com a criação ou a execução de música: o artista ainda mecenizado pela Igreja (Mestre Romão, regente e fracassado compositor de "Cantiga de esponsais"), o criador já inserido na profissionalização da emergente cultura de massas mas desconforme com ela (Pestana, o bem-sucedido autor de polcas que sonha ser sonatista em "Um homem célebre"), o músico dividido entre o instrumento profissional, a rabeca, e o instrumento artístico, o violoncelo (Inácio, em "O machete") e o pobre que exerce a maestria musical como bilhete de entrada em círculos de classe média (Barbosa, o artista popular em "O machete"). John Gledson já notara que em "O machete" combinam-se o "sério e profundo" com o "leve e zombeteiro", ou o "local brasileiro" com o "tradicional europeu" (Gledson, 1988, p. 52). José Miguel Wisnik aponta que "Machado de Assis foi quem primeiro percebeu . . . a dimensão abarcante que assumiria a música popular no Brasil como instância a figurar e a exprimir, como nenhuma, a vida brasileira como um todo" (Wisnik, 2004, p. 79). O estudo de Wisnik reforçou uma percepção minha de que a música seria uma porta de entrada à representação do popular em Machado e uma peça-chave para se compreender a interação entre a cultura erudita e a emergente cultura de massas. Partirei do estudo de Wisnik para chegar a conclusões que não coincidem exatamente com as dele.

Em “Um homem célebre", Pestana simboliza o compositor desajustado que é, no entanto, notável e singular em seu desajuste. Formado nos ideais do sonatismo, abençoado pelos retratos de Cimarosa, Mozart, Beethoven, Gluck, Bach, Schumann sobre o seu piano, Pestana sofre ao tentar compor música clássica e ver que cada ideia era "eco apenas de alguma peça alheia, que a memória repetia, e que ele supunha inventar" (Machado de Assis, 1959, p. 499). A originalidade de Pestana é que no campo ao qual ele era indiferente, senão hostil - o da polca popular - ele é ineludível, indispensável. Pestana reage "vexado e enfastiado" ao sucesso crescente das suas polcas, enquanto "os mestres retratados o fizeram sangrar de remorsos" (id., p. 500). Depois do matrimônio com Maria, cantora e tísica, Pestana 
espera "engendrar uma família de obras sérias, profundas, inspiradas e trabalhadas", relação frustrada entre composição e casamento que já aparecera também em "O machete". A execução que realiza a esposa de uma peça, "Ave Maria", que Pestana acreditava ser de sua autoria, decide em definitivo a "peteca entre a ambição e a vocação". Pestana se dá conta de que se trata de um noturno de Chopin. A peça "sucumbe ao teste do plágio" (Wisnik, 2004, p. 56). Depois da morte da mulher, Pestana tenta infrutiferamente compor um réquiem. Premido pelas dívidas, cede à tentação das polcas comerciais, aceita um contrato para canções de ocasião, compõe "Bravos à Eleição Direta!" para celebrar a vitória dos liberais em 1878 e vive até 1886 , sardonicamente deixando duas polcas, a solicitada para a volta dos conservadores e uma de reserva, "para quando subirem os liberais".

O retrato do músico mais comum na ficção de Machado é o de um ser precário: vitimado pela falta de capital cultural, no caso do músico erudito, ou marginalizado do circuito de reconhecimento simbólico, no caso do músico popular. Nas crônicas, a polca e o mundo do bel canto italiano darão a Machado vislumbres do que Adorno e Horkheimer depois chamariam de indústria cultural. Se é certo que na ficção há um descompasso do músico consigo e com o outro, não dá na mesma ser um violoncelista ou sonatista sem público e ser um chorão, machetista ou batuqueiro ainda sem acesso ao capital simbólico. Enquanto que àquele sujeito, o aristocrático em declínio, a única alternativa é a percepção da queda do prestígio de sua arte ${ }^{1}$, ao sujeito popular parece estar aberta uma fresta de possibilidade de legitimação, ainda que acompanhada de um árduo caminho plagado de preconceitos. Se as práticas musicais populares aparecerão na obra de Machado como índices de falta de sofisticação, elas também deixarão marcas da promessa de uma entrada a um mundo mais moderno e dinâmico, inalcançável para os violoncelos. Mesmo o leigo já está, hoje, acostumado a pensar na música popular que se consolidou no século XX como cifra da nacionalidade, mas nem os leitores especializados costumam pensar na obra de Machado de Assis como a primeira reflexão sobre a onipresença social da música popular no Brasil. É essa a hipótese que nos orienta aqui.

Ganado tengo el pan/hágase el verso: no famoso dístico do cubano José Martí, contemporâneo de Machado e também poeta, ficcionista, drama-

\footnotetext{
${ }^{1}$ Como aponta Raymundo Faoro, “a obra de Machado coincide com o momento histórico em que "a classe de especuladores ganha o posto dominante, o pináculo, transformando-se em plutocracia" (Faoro, 2001, p. 389).
} 
turgo e cronista, já se vislumbra a oposição que angustiará os escritores semiprofissionais do século XIX: por um lado, "sujar as mãos" nos jornais onde se ganha o pão, por outro, escrever o verso imortal e eterno, possibilitado pela suja escrita semanal por encomenda. Ler as crônicas dos literatos do século XIX é mergulhar num mundo onde a arte se mistura com o ofício. "Necessito mais que nunca de ti", diz Machado à sua "pena de cronista" no primeiro texto escrito para O futuro, em 1862: "que tens aprendido desde que te encafuei entre os meus esboços de prosa e de poesia?". . O escritor que "encafua" a crônica entre a poesia e a ficção exerce uma aprendizagem e aguça os ouvidos para o burburinho das ruas. Nas crônicas, mais que nos contos ou romances, Machado dá testemunho do nascimento de uma cultura de entretenimento massivo que ele vê com suspeição: serão constantes as referências ao mundo da música em vias de globalização e em processo de profissionalização, contrastando com o mundo ainda amadorístico da cultura letrada. Na medida em que se consolida uma cultura de canto lírico e de dança de salão no Rio de Janeiro, a música se fará mais presente na escrita de Machado para jornais como $A$ Semana e o Diário do Rio de Janeiro.

Como instrumento de entrada dos escritores no mercado massivo, a crônica é um gênero que traz em si as marcas da autorreinvenção do poeta como um ser de carteira assinada que bate ponto no trabalho. Essa nova realidade lhe confere uma relação privilegiada com o contingente. Ao deparar-se com a produção cultural em série, massiva, o literato não deixa de registrar assombro, admiração e algo de inveja. A literatura aparecerá como a prima pobre nessa comparação com a música produzida para consumo massivo. Em crônica de junho de 1878, Machado toca numa dimensão incipiente da indústria cultural:

"Se eu pedir você me dá?" é o título de uma polca distribuída há algumas semanas. Não ficou sem resposta. Saiu agora outra polca, denominada "Peça só, e você verá". Este sistema telefônico, aplicado à composição musical, não é novo, data de alguns anos; mas até onde irá é o que ninguém pode prever. (Machado de Assis, 1957, p. 213)

O curioso é que no momento em que Machado vê uma característica imemorial das práticas poéticas populares (a estrutura em diálogo, a presença de desafios, a produção em série) revivida num fenômeno urbano

\footnotetext{
2 Sobre o esforço de adaptar-se à temporalidade do cronista, Machado (1957, v. 22, p. 300) diria: "Estou convencido de que esse amigo não foi às corridas. Não foi ou não vai? Na hora em que escrevo - não vai; naquela em que o leitor pode ler estas linhas - não foi. Eu não sei combinar estes tempos da crônica". (Machado de Assis, 1957, v. 24, p. 104)
} 
massivo como a polca, ele encontra na tecnologia uma metáfora para descrevê-la. O telefone como metáfora reapareceria, claro, décadas depois, no momento de constituição (ou de primeira nomeação) do samba, com a gravação de "Pelo telefone", registrada em nome de Donga em 1916.

O cronista não deixa de atentar para a novidade que representava a constituição de uma classe de músicos bem remunerados: "Só o tenor recebe por mês oito contos e oitocentos mil-réis! Não sei que haja na crítica moderna melhor definição de um tenor do que esta dos oito contos, a não ser outra de dez ou quinze" (id., p. 96). São as crônicas que registram quão profundo foi, para Machado, o impacto de ter que falar da arte musical em termos que a tornavam indistinta de uma mercadoria. A dicotomia entre arte e mercadoria é onipresente nas crônicas, mas há que se resguardar contra uma leitura que veja nelas uma simples confirmação do "conteúdo" da ficção. Nas crônicas, a oposição aparecerá de forma mais taxativa, menos ambígua ou irônica: as crônicas serão o espaço de rascunho das hipóteses de Machado sobre os lugares da cultura. Para o escritor que tentava dar conta da notável profissiona-lização da música, a precária profissionalização da literatura deixava a desejar. Numa crônica de 1876 que nota o relativo descaso ante a morte de George Sand, em comparação com a grande comoção que causa a morte de qualquer soprano, Machado aponta:

Ora, expirou há pouco uma mulher, que me hão de conceber tinha um gênio maior que o do soprano referido, mulher que ocupa um dos mais altos lugares entre os prosadores de seu século. Madame Sand nunca venceu tanto por mês. Rendeu-lhe menos Indiana ou Mauprat do que rendem ao soprano de que trato meia dúzia de sustenidos bem sustenidos. (id., p. 97-8)

O espetáculo popular de massas colocou o escritor numa situação paradoxal. $\mathrm{O}$ veículo que possibilitava sua profissionalização era o mesmo que lhe alertava para os limites do profissionalismo. Vários escritores viveram esse dilema, mas Machado percebeu as ramificações: uma profissionalização do escritor que era parasitária da modernização de outras esferas da cultura. $\mathrm{O}$ jornal, espaço onde o escritor iria ganarse el pan para que pudesse depois hacer el verso, seria também o espaço em que se registraria com distância, e não sem certa inveja, um outro profissionalismo, mais moderno, o da emergente música massiva. $\mathrm{O}$ mundo dos pop stars do bel canto italiano sugere a Machado algo dessa dimensão, mas será a polca que cumprirá esse papel de forma definitiva.

A polca é a ponte entre a vivência plebeia e artesanal da música e a dimensão mais propriamente moderna, antecipadora do que seria a in- 
dústria cultural. É escondendo-se sob formas hifenadas (polca-brasileira, polca-lundu ou polca-cateretê) que se constituirá o primeiro grande fenômeno musical popular e urbano do Brasil, o maxixe. A polca tem um lugar privilegiado como prática cultural híbrida, em trânsito, definidora da nacionalidade, que Machado não deixará de registrar na Gazeta de Holanda:

Mas a polca? A polca veio

De longes terras estranhas,

Galgando o que achou permeio,

Mares, cidades, montanhas.

Aqui ficou, aqui mora,

Mas de feições tão mudadas,

Que até discute ou memora

Cousas velhas e intrincadas

Pusemos-lhe a melhor graça,

No título, que é dengoso,

Já requebro, já chalaça

Ou lépido ou langoroso.

As quadras de Machado localizam no amolengamento a contribuição brasileira à polca, gênero que entra como emblema de uma teoria antropofágica da cultura:

Dizem até que, não tendo

Firme a personalidade,

Vamos tudo recebendo

Alto e malo, na verdade

(...)

Ao que eu contesto, porquanto

A tudo damos um cunho

Local, nosso; e a cada canto

acho disso testemunho

O poema escolhe um gênero musical como exemplo privilegiado da hibridez brasileira. Se agregar um "cunho local, nosso" ao importado é uma das características da nacionalidade, então a polca seria o gênero brasileiro por excelência. Mais do que qualquer outra importação, a polca abre-se para um suplemento rítmico contramétrico que o Brasil, rico em 
Idelber Avelar

culturas afro-atlânticas, estaria em posição privilegiada para acrescentar às danças de salão europeias. Ao suplementar a polca no momento de sua execução, o Brasil forjaria sua linguagem musical por excelência, o choro, que derivou da forma alongada e modulada dos grupos musicais de chorões tocarem a polca. Ao suplementá-la no terreno da dança, o Brasil sincoparia, "quebraria" a polca e constituiria seu primeiro gênero massivo urbano, o maxixe. José Ramos Tinhorão aponta referências à polca "em crônicas de 1878, 1887 e 1894, nos romances Ressurreição (1872), Memórias póstumas de Brás Cubas (1878) e Quincas Borba (1889), e em dois contos" (Tinhorão, 1978, p. 54), mas será nessas quadrinhas que Machado fará da polca um emblema antropofágico da nacionalidade, antecipando Oswald de Andrade ao retratar o intercâmbio cultural como digestão e suplementação do importado. É como se Machado dissesse, anacronicamente: depois da polca, tudo é Macunaíma.

Também há, em Machado, um universo de referências à valsa, dança em ritmo ternário (compasso em três por quatro) que operou como um dos únicos espaços públicos de "aproximação que a época oferecia a namorados e amantes" (id., p. 184). Introduzida pela família real portuguesa em 1808, solidificada com a presença de compositores como Sigismund Neukomm entre 1816 e 1821 -, a valsa foi hegemônica na preferência da elite do Rio no período em que se interromperam os espetáculos de ópera, de 1830 a 1845 (Heitor, 1956). De origem campônia, plebeia, a valsa já é, no momento em que Machado a retrata, um marcador de classe aristocratizante. Suas origens populares são visíveis na diferença que ela introduz em relação a danças anteriores, como o minueto, a polonesa ou a quadrilha. Na valsa os bailarinos se encontram nos braços um do outro, com os rostos a poucos centímentros de distância. É o gênero pioneiro na dança enlaçada. Foi perturbadora essa introdução de posições mais eroticamente sugestivas na dança. No momento de sua introdução na Inglaterra, um editorial do The Times de 1816 afirmaria:

Notamos com dor que a dança estrangeira indecente chamada valsa foi introduzida ... na corte inglesa ... Enquanto essa exibição obscena estava confinada a prostitutas e adúlteras, não a julgávamos digna de nota; mas agora que se tenta forçá-la nas classes respeitáveis da sociedade pelos exemplos civis de seus superiores, sentimos que é um dever alertar todos os pais contra a exposição de suas filhas a contágio tão fatal $l^{3}$.

\footnotetext{
${ }^{3}$ The Waltz History. http://www.centralhome.com/ballroomcountry/waltz.htm
} 
Tal como voltaria a acontecer incontáveis vezes (com o samba, o maxixe, o tango argentino, o rock'n' roll), é à pureza da mulher que os moralismos de plantão recorrem como tesouro a ser preservado ante a chegada da dança bárbara. A reação mais virulenta contra a valsa se dá a partir do orgulho do macho ferido. Coincidindo com a aceitação e canonização da valsa na corte, Machado registra a abertura do exercício de um prazer feminino nos salões, que aparecerá, em sua obra, de forma sistematicamente vigiada. "O machete", conto de 1878, dirá algo sobre a sedução e a fascinação da dança.

O reinício da ópera no Rio, em 1845, concide com a introdução da polca, que teria um impacto significativo na história da música brasileira. Interpretada pela primeira vez em 1845, no Teatro São Pedro, a polca se espalharia como febre pelos salões do país. Já em 1846 se constituía uma Sociedade Constante Polca na corte. Em poucos anos, a polca substituiria a valsa nas preferências da elite do Rio de Janeiro. Segundo Tinhorão, o dois por quatro em allegreto da polca, com seus movimentos saltitantes, deu vazão a uma sensibilidade social de euforia pela estabilidade política e prosperidade econômica que era inalcançável pelo movimento mais cadenciado da valsa. Ocorrem dois processos importantes nas preferências musicais de elite do Rio na segunda metade do século XIX: a queda na relevância social da ópera e o paulatino avanço da polca sobre a valsa. Ao contrário da valsa, a polca abriria uma linha de comunicação direta com a música popular.

A passagem ao ritmo binário da polca representou a chegada de uma sintaxe musical mais apta a conversar com a polirritmia afro-brasileira, que naquele momento já se fazia ouvir em quintais e ruas. Essa conversa tem um nome no Brasil: maxixe. As duas décadas em que Machado se consolida como cronista (1860-80) coincidem com o período de transição entre a consolidação da polca abrasileirada e a emergência maldita, reprimida e libertadora do maxixe. O maxixe não é uma forma que tenha se estabelecido no país numa data determinada (como os gêneros importados, a valsa em 1808 e a polca em 1845) nem um padrão rítmico cujo nome tivesse sido contemporâneo ao fenômeno (como seria o caso do samba, constituído enquanto tal aproximadamente entre 1910 e 1933, e nomeado em 1916). No caso do maxixe, há um descompasso entre o fenômeno e sua nomeação, em virtude da censura que sofre a própria palavra. Não é demais recordar que Ernesto Nazareth, ápice da composição musical no Brasil no século XIX, escolheu, para suas polcas maxixadas e maxixes, a evasiva denominação de "tango brasileiro". No final dos anos 1870, o termo maxixe ainda é tabu no Rio de Janeiro, "usado ao tempo para tudo 
Idelber Avelar

quanto fosse coisa julgada de última categoria" (Tinhorão, 1978, p. 59). Evocando um corpo popular e mulato, ele opera como repertório de movimentos corporais proibidos e subversivos.

O maxixe é um daqueles casos singulares em que a dança gera o gênero: "foi, pois, o estilo de tal forma malandra e exagerada de dançar o ritmo quebrado da polca-tango que acabaria por fazer surgir o maxixe como gênero musical autônomo" (Tinhorão, 1978). O que se nomeia aqui como "polca-tango" também foi chamado "polca-lundu", "polca-chula", "polca-cateretê" e "polca brasileira". Esses rótulos designam a forma de tocar a polca europeia que se desenvolvia no Brasil, na qual se deixava ouvir o registro de sensibilidades musicais afro-atlânticas. As décadas de 1860-80, que assistem ao amaxixamento da polca, também testemunham a consolidação do estilo de tocar dos chorões, na base de um solo acompanhado de contracanto e modulações. Tinhorão assinala que a música dos chorões traz um nítido legado do que "se chamara nos fins do século XVIII e início do século XIX de música de senzala" (Tinhorão, 2000, p. 55), introduzindo na polca modulações que ela até então não conhecia. O uso do contracanto dá aos vocais uma estrutura responsorial, marca das práticas musicais afro-atlânticas. Começa a se constituir ali uma música mestiça urbana que remete a um traço das músicas africanas subsaarianas: a interpolação de agrupamentos binários e ternários, ou seja, a utilização de compassos que misturam agrupamentos de duas e de três pulsações.

Essa característica, que começa a invadir os espaços eruditos, receberia um nome: síncope, que já Mário de Andrade identificava como traço que "percorre com constância formidável toda a música americana" e que era "tida em geral como provinda da África" (Andrade, 1987, p. 409). A síncope, conceito naturalizado como algo "africano", nada mais é que a forma encontrada para registrar essa contrametricidade própria das músicas africanas subsaarianas nos cânones escriturais herdados da música erudita europeia: "a notação em partitura não prevê ... a interpolação de agrupamentos binários e ternários. O resultado é que ritmos desse tipo apareceram nas partituras como deslocados, anormais, irregulares (exigindo, para sua correta execução, o recurso gráfico da ligadura e o recurso analítico da contagem) - em uma palavra, como síncopes" (Sandroni, 2001, p. 26). As estruturas musicais contramétricas serão registradas por Machado no uso de verbos como "saracotear" e "pulular" e em adjetivos como "saltitante" e "buliçosa". Assim como a partitura herdada da Europa registra a estrutura contramétrica afro-atlântica como irregularidade, também o vocabulário do escritor recorrerá a termos insólitos para descrever a dança popular. 
O maxixe se dissemina fortalecido pela novidade da dança que permitia o entrelaçamento dos corpos, favorecido pelo contato com os "lundus dançados com umbigadas por mestiços e brancos" (Tinhorão, 2000, p. 56). Partindo dos bailes do Paraíso, onde se reuniam o baixo meretrício e a capadoçagem, até chegar aos bailes de carnaval, o maxixe vai conquistando as camadas mais altas da sociedade. A incorporação ao teatro de revista se dá em 1885 com Arthur Azevedo, na revista Cocota, no Teatro Santana. Em 1883 o maxixe era representado no teatro para um público de classe alta, pelo ator Francisco Correia Vasques, enquanto se disseminava como prática cotidiana das classes populares. A partir do tango "As Laranjas da Sabina", de Arthur Azevedo, na peça República, de 1890, o maxixe iniciaria uma longa carreira de pelo menos 40 anos nos palcos, chegando à Europa em 1905, através do bailarino Duque. Seu declínio no Brasil aconteceria por volta de 1918, ocasionado, segundo Tinhorão, pela "chegada dos fox-trot e charleston" (id., p. 61). Contemporânea do primeiro encontro sistemático entre a música europeia de salão e as tradições polirrítmicas afro-brasileiras, a obra de Machado o registra sob a forma de ecos. Mesmo avessa a vozes populares de perfil mais radical, sua obra capta uma série de sussurros que vêm da rua, do produtor cultural ainda não aceito pelas práticas da elite. "O machete" seria o grande registro da dimensão musical desses sussurros.

É irônico que "O machete", conto que narra a dissolução de uma família, tenha sido publicado no Jornal das Famílias em 1878; é significativo que Machado não o tenha selecionado para compor Papéis Avulsos (1882) ou qualquer outra coletânea. Sexualizado e multicultural, "O machete" é um conto sobre música e adultério. Carlotinha, casada com Inácio, troca o violoncelo do marido pelo machete de Barbosa, durante a emergência da cultura musical urbana do Rio de Janeiro. Um casamento plácido entre o violoncelista Inácio Ramos e sua mulher Carlotinha é interrompido pela chegada de outro homem e seu machete - por convite do próprio Inácio, que viu no machete o complemento para seu violoncelo. As razões de Machado para não incluir o relato nos volumes de contos publicados não se devem, me parece, a uma suposta falta de perfeição do texto. Prefiro arriscar outra hipótese: "O machete", com sua representação debochada de um dos primeiros cornos de nossa ficção e sua associação explicita da sexualidade com a música popular, terminou sendo um relato demasiado perturbador.

Antônio Houaiss (2001) localiza em 1716 a primeira ocorrência do vocábulo "machete" como designação de um instrumento musical: "de origem portuguesa, maior que o cavaquinho e menor que a viola, com 
quatro ou cinco cordas duplas e dedilháveis, afinadas em quintas". Segundo Houaiss, a etimologia do termo se remonta ao espanhol: machete (1550), "estaca, espada ou faca larga e curta", derivado do espanhol macho, "maça, clave". O instrumento já traz a marca de uma nova cultura, boêmia e popular. Se na segunda metade do século XIX a música ouvida pelas elites eram em geral "as óperas, operetas e a música leve de salão: polca ... valsa ... a schottish, a quadrilha, a mazurca" (Cravo Albin, 2003, p. 38), um instrumento como o machete dá testemunho da emergência e consolidação de outra prática cultural: as rodas de chorões.

Implacável, o conto é um dos registros machadianos mais notáveis da irrupção da cultura popular urbana. Inácio Ramos, presa da vocação desde os dez anos, recebe do pai, "músico da imperial capela", rudimentos de música que o tornariam melhor em "bemóis que [n]os verbos" (id., p. 856). Torna-se exímio executor e um "rabequista de primeira categoria". Seu destino e sua queda não são alheios a essa limitação frequente nos intelectuais e artistas retratados por Machado: a de saber copiar e executar, mas raramente criar. Já rabequista, Inácio continua buscando um instrumento que corresponda às "sensações da alma", quando é cativado pelo violoncelo de um músico alemão em excursão no Rio. Torna-se violoncelista e começa a viver a oposição entre a rabeca tocada por dinheiro e sua arte, o violoncelo, para o qual reservava "as melhores das suas aspirações íntimas" (id., p. 857). Inácio replica Pestana, o criador de "Um homem célebre", capaz de conseguir para si uma grande fatia do mercado compondo polcas, mas sempre fracassado em seus desejos de compor sonatas. A diferença entre Inácio e Pestana é que o drama de "Um homem célebre" se limita à tensão entre arte e comércio dentro do personagem, enquanto que o Inácio de "O machete" terá que viver a cisão entre esses termos no interior de um triângulo.

Inácio Ramos é uma espécie de músico erudito condenado à tristeza tropical. Como um autor de "notas fora do lugar"4, ele se encontra em contradição com a experiência. Tocava "a rabeca para os outros, o violoncelo para si, quando muito para sua velha mãe" (id., p. 857). Durante dois anos ninguém ouve a obra; Inácio rompe o silêncio oito dias depois de casado, diante da mulher Carlotinha: "não via a mulher, nem o lugar, nem o instrumento sequer: via a imagem da mãe e embebia-se todo em um mundo de harmonias celestiais" (id., p. 858). A palavra "celestial" invariavelmente aparece em registro irônico e de leve deboche na obra de Machado. Não é diferente aqui, onde ela é usada para caracterizar uma

${ }^{4}$ Aludo aqui à célebre tese de Roberto Schwarz (1988). 
música divorciada do corpo. Quando Carlotinha se lança à celebração da execução com gritos de "lindo", Inácio vê na reação uma ofensa, como se a mulher não houvesse compreendido a profundidade e a melancolia da peça. Onde Inácio queria o descanso e o luto, Carlota era puro entusiasmo. Onde ele queria coqueiro, ela era revólver. Esse descompasso entre a recepção real da música e a recepção idealizada pelo artista erudito já anuncia a chegada do terceiro, do tocador de machete.

Um par de transeuntes, estudantes de direito em férias, ouvem a música de Inácio e lançam gritos de "bravo, artista divino!". Os dois estudantes são Amaral, "alma cheia de música alemã e poesia romântica" e seu companheiro Barbosa, "apenas um espírito medíocre, avesso a todas essas cousas, não menos que ao direito que aliás forcejava por meter na cabeça" (id., p. 860). Só numa visita subsequente Amaral menciona que o amigo Barbosa também é músico. Vale citar o diálogo de Inácio com Barbosa como registro do horizonte de expectativas de um violoncelista encontrando a cultura musical popular-urbana:

- Que instrumento toca?

- Adivinhe.

- Talvez piano...

- Não.

- Flauta?

- Qual!

- É instrumento de cordas?

- É.

- Não sendo rabeca . . . disse Inácio como a esperar uma confirmação.

- Não é rabeca, é machete (id., p. 860-1).

Aqui Machado dirige a atenção do leitor para a inadequação de seu personagem à experiência: Inácio é músico e vive no Rio de Janeiro no fim da década de 1870, mas simplesmente não possui registro de instrumentos de cordas além dos usuais na música burguesa de salão. Passa ao largo do processo de constituição de uma linguagem musical brasileira nas rodas de chorões. A escolha do instrumento de Inácio não poderia ser mais contrastante com o machete que adentra a sala: o violoncelo é um instrumento que indicia uma música erudita algo anquilosada e melancólica, em descompasso inclusive com as preferências da elite dos salões. Quando Inácio convida Barbosa para uma demonstração no machete, trata-se quase que de um chamado a uma exibição folclórico-etnográfica que não mereceria o nome de arte. Até, é claro, que começa a performance: "Barbosa tocou-a, não dizer com alma, mas com nervos. Todo ele acompanhava a 
gradação e variações das notas; inclinava-se sobre o instrumento, retesava o corpo, pendia a cabeça ora a um lado, ora a outro, alçava a perna, sorria, derretia os olhos ou fechava-os nos lugares que lhe pareciam patéticos" (id., p. 861). A forma como Inácio introduz o machetista tem um tom de etnógrafo curioso pesquisando o selvagem dócil. A performance de Barbosa, no entanto, é a do mau selvagem, aquele que não se adequa ao lugar que lhe reservara a antropologia: "o contraste é completo entre o show de exterioridade do virtuosístico e esperto tocador de cavaquinho e o aspecto sóbrio e concentrado do praticante de violoncelo, alheio a qualquer apelo exibicionista e todo voltado à essencialidade da música, para transceder o ofício em arte" (Wisnik, 2004, p. 24).

Para Machado, o problema é que essa arte, ao contrário daquela do performático machete, já se encontra divorciada da experiência. O machete de Barbosa passa a ser conhecido da vizinhança; os saraus eram estimulados por Carlotinha. Barbosa sugere que Inácio programe um concerto. Este cede, agendando uma apresentação em que tocaria "uma das peças já compostas por ele, e duas de dois mestres que escolheu entre as muitas" (Machado de Assis, 1959, p. 862). Aqui se confirma que Inácio era o autor de duas composições; muitas eram as obras de "mestres" que ele poderia reproduzir. Note-se que nisso ele tem o mesmo destino de Pestana, de "Um homem célebre", capaz de criação no ramo da arte "ligeira", de entretenimento, e que no terreno de seu desejo, o sonatismo erudito, só consegue reprodu-zir. Há uma diferença importante entre a satisfação de Inácio como executor de peças clássicas e a perene insatisfação de Pestana com a impossibilidade de compor sonatas. Mas eles coincidem na relação reprodutiva com a música erudita. Em "O machete", o contraste entre Inácio e Barbosa é uma cisão entre o artista que reproduz os mestres e o artista que executa composições de autoria pessoal, coletiva ou desconhecida, mas sempre com liberdade de improvisação sobre elas. Mais além de qualquer preconceito de Machado ante a cultura popular, "O machete" anuncia e celebra a beleza dessa promessa, a do artista livre da angústia da autoria.

O poder de sedução do machete deixa Inácio cada vez mais melancólico, até que ele surpreende Amaral com a declaração de que "estou arrependido do violoncelo; se eu tivesse estudado o machete!" (id., p. 863). Formado no idealismo estético e trabalhando com uma oposição já arcaica entre o valor artístico e o não valor do entretenimento, Amaral não consegue compreender "que rivalidade era aquela entre a arte e o passatempo" (id., ibid.). O narrador se refere à separação entre arte e entretenimento em discurso indireto livre, como que "na cabeça" de um 
personagem. Não se deve, pois, concluir que o autor subscreveria uma separação tranquila entre os dois termos. À medida que se desenrola o conto, solapa-se a confiança do narrador na estabilidade dessa dicotomia.

Machado certamente teve seus preconceitos com respeito à cultura popular, mas o quadro que sua ficção nos oferece é o do desmoronamento da possibilidade de separação clara entre a arte sancionada como esteticamente válida, por um lado, e o entrenimento, por outro. Amaral e o próprio discurso indireto livre do narrador gostariam de manter a distinção intacta nesses termos, é certo. Mas isso não nos autoriza a daí deduzir que ela assim permanece para Machado. Aqui há uma diferença entre minha leitura e o estudo de Wisnik, para quem Machado "supõe e promove a identificação positiva com o mundo representado pelo violoncelo, em clara oposição ao mundo representado pelo cavaquinho" (Wisnik, 2004, p. 25). Por mais que seja detectável em Machado alguma nostalgia do tempo em que a arte erudita ainda não havia perdido seu capital cultural, essa identificação é menos clara e automática do que nos faria crer Wisnik. O conto é, afinal, uma grande parábola acerca da inépcia dessa arte de câmara.

Inácio já sabia que havia perdido Carlotinha ali, no momento em que Amaral se esforçava para compreender como o passatempo do machete poderia rivalizar com a arte do violoncelo. Quando, depois do regresso de Amaral e Barbosa a São Paulo, chega a notícia de que estariam de novo no Rio, o leitor já tem elementos para adivinhar o fim. Amaral fica o período combinado e volta. Barbosa adoece, recebe uma carta que "lhe obriga a ficar algum tempo" e quando visita Inácio e Carlotinha, a mulher ouve "alegre a notícia" enquanto que "o rosto de Inácio não tinha nenhuma expressão" (Machado de Assis, 1959, p. 864). Nos novos serões, o machete reina inconteste: "o machete deve ser instrumento triste, porque a melancolia de Inácio tornou-se cada vez mais profunda" (id., ibid.). Quando Amaral retorna para visitar o casal, só encontra Inácio com o violoncelo e uma criança de alguns meses ao pé do instrumento, "dominada ao que parece pela música". Ele ouve o relato da boca do próprio Inácio: "ela foi-se embora, foi-se com o machete. Não quis o violoncelo, que é grave demais. Tem razão; o machete é melhor" (id., p. 865). Como notou Wisnik, as duas frases finais do conto replicam a fórmula do melodrama: "A alma do marido chorava mas os olhos estavam secos. Uma hora depois enlouqueceu".

Considerando que a raíz de macho ressoa paronomasicamente no termo machete, teríamos que tirar as consequências da menção ao melodrama. Estamos diante de um enlouquecimento clichê, réplica da fórmula 
Idelber Avelar

melodramática, mas no melodrama esse enlouquecimento ocorre à mulher. É raríssimo que a resolução via enlouquecimento se aplique ao herói masculino. Inácio, claro, é um personagem feminizado, e por isso pode sofrer a pena reservada para a mulher no gênero e ainda assim manter intacto o efeito melodramático. Mas é esse mesmo o deslocamento imposto por Machado ao melodrama: dentro de uma fórmula genérica caracterizada pelo final feliz, Machado escolhe armar um narrador que fala, em discurso indireto livre, do ponto de vista da vítima, esta sendo já não propriamente um vilão, mas um incauto derrotado pelas circunstâncias.

A etimologia de melodrama - que poderíamos glosar como "mímese teatral via música" - indica que o gênero manteria, de alguma forma, a memória das origens da tragédia na música (Nietzsche, 1978). Naturalmente, o herói melodramático tem pouco em comum com o herói trágico: enquanto que este se encontra isolado da sociedade e sua trajetória culmina na impossibilidade de impedir o desastre implícito e enraizado nas estruturas sociais que estão mais além de seu controle, o herói do melodrama é normativo e alegoriza a incorporação à sociedade. O herói melodramático traz um senso de virtude inata, mas ao contrário do herói romântico, esse senso interior "não o leva a uma oposição byroniana à ordem social: nesse mundo, os ditados do puro coração são sempre consoantes com os da sociedade" (Allen, 1991, p. 82). O resgate da mulher - clichê narrativo por excelência do gênero - não é nunca, no melodrama, contraditório com as estruturas sociais estabelecidas. Pelo contrário, o tema central do gênero é a "socialização do profundamente pessoal" (Brooks, 1995, p. 227). Daí não se segue para mim, como pareceria para Wisnik, que o melodrama é um gênero necessariamente conservador e conformista. $\mathrm{O}$ fato de que o tema central teatralize uma incorporação não problemática à ordem social vigente não quer dizer que, paralelamente a ele, não se esteja produzindo toda sorte de efeitos perturbadores e subversivos.

Se é correto que se vê em "O machete" o "pressuposto implícito da superioridade da cultura letrada, isenta dos apelos fáceis da música vulgar" (Wisnik, 2004, p. 25), a identificação com o mundo da alta cultura está aqui atravessada pela ironia. A cultura "superior" gera um personagem que é um dos primeiros cornos de nossa ficção urbana, abandonado pela mulher e derrotado pelo descompasso entre a alta música de câmara e a realidade do Rio de Janeiro de fins do século XIX. Barbosa, descrito como "medíocre" por um narrador que compartilha o pressuposto implícito da superioridade da cultura letrada, triunfa porque traz um saber musical vinculado à experiência. Mais que um ou outro traço de preconceito ante a cultura popular que inevitavelmente encontraremos no narrador, há que 
se notar que: 1) Inácio reproduz peças alheias, não compõe, mantém com a tradição uma relação reverente, enquanto Barbosa toca peças anônimas, coletivas ou próprias, exercendo sobre elas improvisação pessoal; 2) o violoncelo pressupõe um corpo estático, enquanto que a musicalidade do machete é inseparável de uma performance corporal dinâmica; 3) o violoncelo pede ao ouvinte uma escuta recatada, enquanto que o machete ativamente o convida a participar da produção musical; 4) o valor da arte de Inácio vem de um capital cultural residual, oriundo de uma arte outrora hegemônica e agora decadente, enquanto que a arte de Barbosa é emergente. A relação entre as diferentes esferas culturais é, então, não só dinâmica mas de dinamismo dialético. Qualquer alteração no estatuto de uma das esferas provoca um rearranjo na posição das demais. Mais que pressupor a superioridade de uma cultura sobre a outra, o conto faz a crônica de uma queda e de uma transição. Serão os primeiros acordes da música popular urbana de rua, do maxixe, que marcarão em definitivo o divórcio entre o sonatismo erudito e a experiência social real.

A mirada de Machado sobre o campo musical brasileiro do século XIX não é, portanto, binária. Como num padrão rítmico afro-atlântico, os acasalamentos são produzidos e desfeitos de forma a gerar não somente pares, mas também triângulos. Inácio é "autenticamente erudito" somente na medida em que a erudição pode ser autêntica em terras periféricas, ou seja, ele é um perfeito executor, jamais criador. É inautenticamente autêntico. Pestana é o emblema machadiano da autoconsciência dessa inautenticidade. Angustiado por não poder ser criador onde queria ser e, ao fim, irônico, reconciliado com a fabricação de mercadorias, ele é o autenticamente inautêntico. Traz à periférica existência do músico erudito tupiniquim (sua "inautenticidade") consciência e lucidez que lhe permitem transcender a derrota de sua vontade artística e realizar algo para o qual ainda não há registro. Mas se nos ativéssemos a esses dois personagens, ainda estaríamos restritos ao círculo vicioso da cultura de elite periférica. Trata-se de um círculo vicioso do qual Inácio não se dá conta, mas Pestana sim: ser autêntico para a sua arte só ao preço de ser inautêntico para o mundo. Esse dilema não é uma aporia universal inescapável, mas a contingência específica de uma cultura de elite colonial e pós-colonial. A saída que encontra Pestana é recolher-se ao fracasso do projeto de um sonatismo tupiniquim e acionar pelo menos alguma ironia, alguma galhofa, no momento de ser absorvido pela indústria da música que ele desprezava.

Mas é com a entrada de um terceiro personagem que o círculo vicioso da autenticidade inautêntica se desfaz: Barbosa, o músico das classes 
Idelber Avelar

populares, interrompe a peteca entre ambição e vocação na medida em que representa uma produção cultural onde essas duas coisas não são antagônicas. Barbosa pode quebrar o círculo vicioso porque inicia o conto em total inautenticidade, em ausência completa de qualquer capital cultural: lembre-se aqui o interrogatório de adivinhações a que Inácio o submete, tentando descobrir qual era o instrumento que ele tocava. A ascensão de Barbosa não implica nenhuma concessão ou abraço do inautêntico como fatalidade do mundo. Trata-se de uma conquista de terreno, uma redefinição da autenticidade. Inicialmente invisível no campo cultural de elite, a prática popular vai penetrando-o. A música é, sem dúvida, a arte onde esse processo ocorre com mais visibilidade e força no Brasil. A obra de Machado, quando lida no contraponto entre ficção e crônica, se revela a grande reflexão que a literatura dedicou ao processo em que o popular vai tomando dimensões porosas, ubíquas, não facilmente localizáveis. A trajetória de Barbosa alude precisamente a essa consolidação das práticas afro-mestiças rumo à sua absorção pela cultura de elite.

A obra de Machado de Assis, que foi com frequência acusada de ignorar as classes populares, nos ofereceu o esboço de um mapa dos albores da constituição de um campo genuinamente popular e urbano na música brasileira. Essas pegadas do popular demonstram que os dilemas de autenticidade nos quais estavam imersos tantos personagens machadianos não tinham nada de universais ou essencialmente humanos: eram dilemas relacionados à construção de uma cultura de elite numa sociedade periférica escravocrata. A ficção mostra que a ruptura do círculo vicioso da cultura da elite periférica só ocorreria pela entrada de um sujeito exterior, não representado no círculo. Seria um exagero ver em Machado qualquer traço de celebração triunfante da entrada do cavaquinho aos nossos salões de elite, mas foi ele quem primeiro compreendeu a dimensão do que aquela introdução representava. Sem trair o ceticismo que era sua marca registrada, ele não deixou de saudar esse novo ator que adentrava o tabuleiro com um sorriso de canto de lábios, quase alegre.

\section{Referências bibliográficas}

ALLEN, Robert G. (1991). Horrible Prettiness: Burlesque and American Culture. Chapel Hill: University of North Carolina Press.

ANDRADE, Mário de (1987). A melodia do boi e outras peças. São Paulo: Martins.

BROOKS, Peter (1995). The melodramatic imagination: Balzac, Henry James, Melodrama, and the Mode of Excess. New Haven: Yale University Press. 
CRAVO ALBIN, Ricardo (2003). O livro de ouro da MPB: A história da nossa música popular de sua origem até hoje. Rio de Janeiro: Ediouro.

FAORO, Raymundo (2001). Machado de Assis: a pirâmide e o trapézio. 4. ed. São Paulo: Globo.

GLEDSON, John (1988). “Os Contos de Machado de Assis: O machete e o violoncelo". In: ASSIS, Machado de. Contos: uma antologia. São Paulo: Companhia das Letras.

HEITOR, Luiz (1956). 150 anos de música no Brasil (1800-1950). Rio de Janeiro: José Olympio.

HOUAISS, Antônio et al. (2001). Dicionário Houaiss de língua portuguesa. Rio de Janeiro: Objetiva.

MACHADO DE ASSIS, José Maria (1959). Obra completa. v. 2. Rio de Janeiro: Aguilar.

(1957). Obras completas. 31 v. Rio de Janeiro: W.M. Jackson.

NIETZSCHE, Friedrich (1978). A origem da tragédia no espírito da música. Trad. Álvaro Ribeiro. Lisboa: Guimarães.

SANDRONI, Carlos (2001). Feitiço decente: transformações do samba no Rio de Janeiro, 1917-1933. Rio de Janeiro: UFRJ/Zahar.

SCHWARZ, Roberto (1988). Ao vencedor as batatas. 3. ed. São Paulo: Duas Cidades.

TINHORÃO, José Ramos (2000). A música popular no romance brasileiro. São Paulo: Editora 34.

(1978). Pequena história da música popular brasileira: da modinha à canção de protesto. Rio de Janeiro: Vozes.

The Waltz History. http://www.centralhome.com/ballroomcountry/waltz. htm Acesso em 07 de setembro de 2009.

WISNIK, José Miguel (2004). "Machado Maxixe". In: Sem receita. São Paulo: Publifolha. p. 79.

Recebido em setembro de 2010.

Aprovado para publicação em janeiro de 2011.

\section{resumolabstract}

Entre o violoncelo e o cavaquinho: música e sujeito popular em Machado de Assis

Idelber Avelar

O artigo discute a tensão entre a cultura erudita, a emergente cultura popular e a incipiente cultura de massas através de uma análise do estatuto da música na obra de Machado de Assis. Dedicando atenção especial a um conjunto de crônicas 
Idelber Avelar

sobre o tema e aos contos "Um homem célebre" e "O machete", o artigo propõe que a obra de Machado foi a primeira reflexão literária sobre a música como cifra privilegiada da nacionalidade.

Palavras-chave: música, cultura popular, Machado de Assis

\section{Between the cello and small guitar, music and popular subject in Machado} de Assis

Idelber Avelar

The article discusses the tension between high culture, the emerging popular culture, and the incipient mass culture through an analysis of the status of music in Machado de Assis's work. Devoting special attention to a set of newspaper chronicles and to the stories "Um homem célebre" and "O machete", the article postulates that Machado's work was the first literary reflection on music as a privileged cipher of nationality.

Key words: music, popular culture, Machado de Assis

Idelber Avelar - "Entre o violoncelo e o cavaquinho: música e sujeito popular em Machado de Assis". Estudos de Literatura Brasileira Contemporânea, n. 37. Brasília, janeiro-junho de 2011, p. 171-188. 